\title{
Coatings as the useful drug delivery system for the prevention of implant-related infections
}

\author{
Chenhao Pan ${ }^{1}$, Zubin Zhou ${ }^{1}$ and Xiaowei $\mathrm{Yu}^{1,2^{*}}$ (D)
}

\begin{abstract}
Implant-related infections (IRIs) which led to a large amount of medical expenditure were caused by bacteria and fungi that involve the implants in the operation or in ward. Traditional treatments of IRIs were comprised of repeated radical debridement, replacement of internal fixators, and intravenous antibiotics. It needed a long time and numbers of surgeries to cure, which meant a catastrophe to patients. So how to prevent it was more important than to cure it. As an excellent local release system, coating is a good idea by its local drug infusion and barrier effect on resisting biofilms which were the main cause of IRIs. So in this review, materials used for coatings and evidences of prevention were elaborated.
\end{abstract}

Keywords: Implant-related infections, Coating, Osteomyelitis, Local drug delivery system, Biofilm

\section{Background}

Implant-related infections (IRIs) are the result of bacteria adhesion to an implant surface and subsequent biofilm formation at the implantation site [1]. The incidence of IRIs in orthopedic trauma patients was from 5 to $10 \%$ depending on the severity of the injury, condition of soft tissue, and the type of fracture [2]. It remains challenging and expensive to treat IRIs, despite advances in antibiotics and new operative techniques. The traditional management of IRIs includes irrigation and debridement, obliteration of dead space, intravenous antibiotics, and removal of the hardware [3]. Each year, 750,000-1,000,000 IRIs occur in the USA, and the government needs to spend more than $\$ 1.6$ billion to cover the expense of the excess hospital charges [4]. Especially, with the widely use of orthopedic implants, the number of infected implants was continued to increase [5]. Even if the infected implants can be successfully removed by secondary surgery, the functionality of the limb and the fracture healing may be

\footnotetext{
* Correspondence: yuxw@sjtu.edu.cn

Chenhao Pan and Zubin Zhou should be considered as equal first coauthors. Chenhao Pan and Zubin Zhou contributed equally to this work.

${ }^{1}$ Department of Orthopaedic Surgery, Shanghai Jiao Tong University

Affiliated Sixth People's Hospital, Shanghai 200233, China

2Department of Orthopaedic Surgery, Shanghai Sixth People's Hospital East

Campus, Shanghai University of Medicine and Health Sciences, Shanghai 201306, China
}

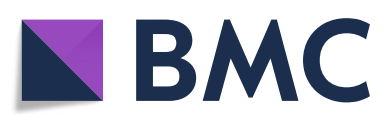

(c) The Author(s). 2018 Open Access This article is distributed under the terms of the Creative Commons Attribution 4.0 International License (http://creativecommons.org/licenses/by/4.0/), which permits unrestricted use, distribution, and reproduction in any medium, provided you give appropriate credit to the original author(s) and the source, provide a link to the Creative Commons license, and indicate if changes were made. The Creative Commons Public Domain Dedication waiver (http://creativecommons.org/publicdomain/zero/1.0/) applies to the data made available in this article, unless otherwise stated. tions such as amputation, joint arthroplasty, or arthrodesis.

So how to prevent the occurrence of fatal IRIs is more important than the treatment. IRIs are typically caused by microorganisms which grow in biofilms and adhere to the implant surface in a highly hydrated extracellular matrix. Avoiding biofilms forming can effectively prevent or treat IRIs [6-9]. As the elective surgery could not be performed under an absolutely sterile environment, bacteria may prefer to adhere to the surface of the bioinert titanium implants and form biofilms, especially when the host's immunological defense functions are compromised and/or the systemic antibiotic prophylaxis is not very effective $[10,11]$. Bacteria which can resist immune responses in biofilms were much less susceptible to antibiotics [12]. Therefore, it is difficult to truly eliminate the biofilm infections and, typically, there are chronic recurring symptoms, even after antibiotic therapy. So the prevention of the growth of nosocomial pathogens is more important than the elimination of the biofilm in IRIs.

Because of the restrictions of traditional systemic drug treatment of bone infection, such as poor effect or hepatorenal toxicity, drugs for IRIs should be performed locally and specifically for implants sites at optimal concentrations over appropriate stages [13]. 
Numerous strategies have been attempted to prevent and treat IRIs by either implant surface fabrication or incorporation of antibiotics into the implant devices. Recent developments in material science showed that implants with biodegradable polymer coatings can be used as controllable means to deliver antibiotics in a sustained fashion. Polymer coatings are capable of completely releasing all antibiotics in a sustained fashion thus minimizing any local or systemic toxicity associated with high fluctuating antibiotic concentrations. For example, Buchholz et al. [14] reported that implant with a synthetic polymers coating as a local drug delivery system significantly reduced the infections and representing a promising approach in the treatment of IRIs. One of the main advantages of implant surface coating-mediated local drug delivery is keeping other parts of the body out of affected so as to avoid serious systemic side effects [15]. A sustained and high antibiotic concentration over minimal inhibitory concentration (MIC) of pathogenic bacteria at the implant site is expected to inhibit bacterial adhesion, colonization, and biofilm formation [16].

The antibacterial implant coating can be divided into calcium or silicon bone cements, polymer hydrogels, and antibacterial ion coatings based on the materials selected by different manufacturing processes like spraying, smearing, and electroplating $[17,18]$. In this review, we will focus on (1) implants coated with antimicrobial substances and (2) the usage of coating in prevention of IRIs.

\section{Mechanism of the IRIs-biofilm}

Biofilms are aggregates of microorganisms as a selfproduced matrix of extracellular polymeric substances (EPS) where bacteria are frequently embedded. EPS adherent to the medically surface (skin, implants, wearing) are accounting for most of microbial infections in the internal fixation devices [16]. Bioinert surfaces attract the biofilm formation [18-20]. The ligand of bacterial fimbriae can be bound to electrovalent bond or hydrophobic bond on the surface of the material. The factors of a surface that determine initial bacterial attachment are its hydrophobicity and roughness [19-21].

In most previous studies on bacterial adhesion on titanium and ceramic surfaces, the quantity of bacterial adhesion showed a direct positive correlation with surface roughness [22-24]. From an atomic force microscopy (AFM) viewpoint, most surfaces are rough and all kinds of surfaces provide adequate conditions for bacterial adhesion [25]. According to the thermodynamic model of microbial adhesion, hydrophobic materials are preferentially colonized by hydrophobic bacteria [26-28]. Consequently, the adhesion properties of different bacteria are affected by the hydrophobicity of the bacterial cell surface $[29,30]$. Both $S$. aureus and Methicillin-resistant Staphylococcus aureus (MRSA) which are common bacteria in IRIs are known to prefer hydrophobic surfaces
[31, 32]. Titanium implants are often bioinert, smooth $(\mathrm{Ra}=280 \mathrm{~nm})$ but enough for bacterial adhesion [33] and hydrophobicity to prevent blood clotting. Thus, biofilm formation occurs commonly [22-33].

Biofilms are complicated systems with high microorganisms' densities, ranging from $10^{8}$ to $10^{11}$ bacteria $\mathrm{g}^{-1}$ wet weight [12]. Most of the biofilm biomass comprises hydrated EPS instead of bacteria. The intermolecular interactions among EPS components originating from self-organization of EPS matrix determine the mechanical characteristics and the biological activity of the matrix in the biofilm [12]. The biofilm architecture formation is a continuous process that creates a micro spatial organization where bacteria clusters present in the biofilm in micro colonies. As the ramparts of bacteria, biofilms have the feature of antibiotics tolerance.

Antibiotics tolerance of biofilms is due to the properties of the biofilm matrix and of the slow growth which occurs in biofilms. The components of EPS matrix can deactivate antimicrobial substances diffused through the biofilm as diffusion-reaction inhibition [34, 35]. Antimicrobial resistance may be promoted by diffusion-reaction inhibition form biofilms through decreasing the effective concentration of antimicrobials that bacteria are exposed to. On the other side, dormancy and slow growth rates have been considered to be ways of bacteria survival in biofilms being exposed to antimicrobials for a long time [36]. The formation and antibiotics resistance of biofilm is time-dependent. The initial bacterial attachment (within an hour) is crucial for the biofilm formation [37-39]. Cell wall-anchored (CWA) proteins of bacteria promote attachment to surfaces in the following $24 \mathrm{~h}$ bacteria adhesion stage. The scanning electron microscope (SEM) revealed implants surface was comprised of bacteria clusters always associated with fibrils, which was presumed as fibrin, and surrounded by diameter host cells [35, 37]. When the bacteria are anchored to the implants, biofilm formation begins to develop. There was a new structure which was called "lacunae" till day $7[15,35]$. The lacunae is the shallow depressions consistent with the size of bacteria, which meant the matrix spaces left by dispersed bacteria. The accumulation of bacteria during biofilm formation is attributed only to the polysaccharide intercellular adhesin (PIA) [38-40]. Next, the biofilm proliferation and maturation remodeling by phenol-soluble modulins (PSMs) begin [41]. After 14-28 days, empty lacunae and a few bacteria were the main morphological characteristics of EPS matrix. This phenotype of EPS matrix remained the same till 6 months post-implantation and showed an unexpectedly outstanding stability of EPS mature biofilm in chronic implant-related infection [35]. In summary, typical biofilm formation is first shaping at day 7 and its growth diffusion peaks covering $30-40 \%$ of the implant is at 2 weeks. 
Unlike the distinct biofilm formation phenotypes in vitro, the in vivo biofilm formation comprised of strains is hard to be indistinguishable [42]. The biofilm formation in vivo takes longer time than in vitro, which may be due to the "race to surface" between bacteria and host cells. Bacterial attachment and biofilm formation stage lasted $12-24 \mathrm{~h}$, and the biofilm proliferation and maturation lasted 36-72 $\mathrm{h}$ for completion [43, 44]. The early infection may be defined up to 3-4 weeks during which debridement and antibiotic therapy with the retained stable implants were performed in the traditional management perspective $[45,46]$. The residual biofilms on retained implants may cause the recurrence of IRIs in many clinical cases. Bioinert polymer coatings like polymethylmethacrylate (PMMA) [47] with antibacterial agents have been used to prevent early fibrin and bacteria adhesion through its barrier and antibacterial effect for IRIs [48, 49].

Over time, the complete biofilms are gradually formed, so is the antibiotic resistance. On the basis of time- and dose- dependent effect of antibiotic susceptibility [5053], ideal cumulative prevention and cure antibiotics release kinetics of the coatings should have the releasing peak over the minimal bactericidal concentration (MBC) during 7-14 days that prevent biofilm formation followed by sustained release between the MIC and MBC over several weeks. By inhibiting the biofilm formation, cells are in a dominant position in the competition against bacteria for growth, so the ideal releasing should have the concentration above MIC over at least 28 days.

At least $1 \%$ bacteria in stationary phase in biofilms are tolerant to antibiotics [54]. As time goes on, more bacteria in the biofilm moved into the stationary phase. Hence, for some kinds of antibiotics like vancomycin, antibiotics tolerance of biofilms showed temporal correlation, which denoted that higher tolerance was shown in older biofilms for these antibiotics as well as metal nanoparticles like Ag [34]. Moreover, biofilms would always die from the outside-in instead of the inside-out [53]. According to the characteristics of biofilm, the treatment is more difficult than prevention. Depending on the type of fracture and contamination of the trauma, second operation for IRIs may be avoided by the use of coating with the ideal antibiotics release curve for prevention.

\section{Main components of coating for IRIs Bone cement coatings}

Various forms of PMMA bone cements and the beads made of it with antibiotics have been used for more than 40 years in hip replacement or in acute and chronic osteomyelitis $[45,47,55,56]$. There are several premixed cements that have been allowed the clinical use by American Food and Drug Administration (FDA): DePuy ${ }^{\odot}$ (DePuy Orthpedics), Cobalt ${ }^{\mathrm{TM}}$ G-HV (Biomet), Cemex ${ }^{\odot}$
Genta (Exactech), Palacos ${ }^{\circledR}$ G (Biomet), and Simplex ${ }^{\oplus}$ P (Stryker Orthpedics). However, these FDA approved antibiotics eluting PMMA bone cements are more appropriate being used as a preventative measure than for the treatment because of their lack of effect on active IRIs due to limited and burst release of embedded antibiotics $[57,58]$. Antibiotics release from PMMA cements is mainly due to the diffusion through surface roughness, superficial pores, and surface erosion [46, 58, 59]. The release characteristic of PMMA was typically performed as a biphasic phase which included a burst head of initial release and a continued tail of ineffective release for weeks or months. The mechanical strength of PMMA is satisfactory, but the low efficiency of the local drug release is the main barriers for its clinical use in IRIs. Therefore, a variety of new biomaterials have been developed and manufactured as alternative antibiotic-eluting bone cements.

Calcium phosphate cements (CPC), beta-tricalciumphosphate $(\beta-\mathrm{TCP})$ and hydroxyapatite (HA) are the calcium phosphate materials. The calcium phosphate materials are degradable and the end products are calcium and phosphate $\left(\mathrm{Ca}^{2+}, \mathrm{PO}_{4}{ }^{3-}\right)$ that are biocompatible, bioactive, and stimulate new bone growth [59-62]. The injectable CPCs are now commercial available that can be solidified after implantation. [60, 61]. There are commonly two phases before the CPCs solidified: the particles and the liquid for better performance. CPCs have the ability of self-set, self-molding, and no exothermic reaction which may be harmful for the bone and incorporated drug [59, $62]$. The slow biodegradation in vivo and poor biomechanical strength have restricted the clinical application of CPCs [58]. In addition, the microstructures of CPCs are dense, lacking of macroporosity that are obviously not suitable for the adhesion, penetration, and colonization of cells and tissue regeneration [58].

Antibiotics, such as gentamicin [46, 63-66] and vancomycin $[67,68]$, can be mixed in the liquid phase of calcium phosphate cement, HA, or $\beta$-TCP [46] against $S$. aureus and MRSA. The apatite cements are made up of microcrystals that have a better biological performance in size and formation than HA particles [63], and show better antibacterial activity. HA nanoparticles can be propagated by wet chemical precipitation and show good bactericidal effect for implant-related pathogens through toxic effect of damaging bacterial membrane [69-71]. It was reported that a drug-chitosan compound was filled in the porous HA matrix and subsequently coated onto the implant smooth surface to obtain a $\mathrm{Ti}_{6} \mathrm{Al}_{4} \mathrm{~V}$ implant with drug-chitosanHA-coating [72-74]. The burst releasing peak continued in the first several hours, and the continued release were covered the post-operative time of perioperative period or 4-8 days. The rest releasing was lasting for more than 1 month. Though $\mathrm{HA}$ have better 
biomechanical properties, $\beta$-TCP seemed to be more suitable for drug release. Another coatings comprised of HA and TCP were defined as bi-phasic calcium phosphates (BCP). More ions dissolved in the $\mathrm{BCP}$ in the local releasing, which meant more carbonate hydroxyapatite on the surface [75]. A $\beta$-TCP coating contained doxycycline (BonyPid ${ }^{\mathrm{TM}}$ ) was described to form a steady, zero-order rate releasing up to 30 days to be capable of eliminating the contaminating bacteria [70]. Moreover, poly(lactic acid)(PLLA)/ $\beta$-TCP coating presents a good result of infection as manifested by the microbiological, radiological, and histological analysis $[67,76]$. At present, the releasing profiles of FDA-approved antibiotic eluting bone cements have the limitations of burst and limited release that are not sufficient to reach a desired constant and long-term sustained release effect to satisfy time- and dose-dependence of biofilms prevention.

\section{Hydrogels coatings}

Hydrogels are usually prepared from natural to synthetic polymers with high degree of hydration and represent promising biomaterials for tissue engineering and regenerative medicine. One class of natural polymers is polysaccharides (e.g., dextran, alginate, chitosan, fibrin, and proteins gelatin). Synthetic polymers include polyethylene oxide (PEO)/polyethylene glycol (PEG), poly (vinyl alcohol) (PVA), poly (acrylic acid) (PAA), and others [49]. Implant surface with PEG and/or PEO coating can endow the ability of anti-bacteria adhesion [77, 78]. There was a report that the inclusion of arginine-glycine-aspartic acid (RGD) array restored the function of local osteoblasts that were damaged by some synthetic polymer coatings [79]. A solubilizing surrounding was offered for the antimicrobials dissolution in local delivery system by the hydrophilic characteristic of hydrogels. Several antibiotics, like ciprofloxacin [80], amoxicillin [81], and gentamicin [82] can be embedded in the bioactive hydrogels. Hydrogels were recently designed by self-assembly formation of tripeptide (D)Leu-Phe-Phe with the incorporation of ciprofloxacin $[49,80]$. During the self-assembly process, it showed that the antimicrobials played an active role in process to incorporate into the hydrogels formation directly. The non-covalent bond contributed to the antimicrobials integration in peptide structure $[48,49]$. The final release was indicated to reach the effect of anti-infection.

The antibacterial properties of chitosan is due to the combination between positively charged amino groups of chitosan and negatively charged bacterial membranes, leading to bacteria membrane leakage [83]. However, because of the displayed weak positive charges on chitosan, coating with chitosan reveal only limited antibacterial effects [84]. Furthermore, the physical and chemical characteristics of chitosan are poorly for embrittlement at room temperature and in acid dissolution environment [85]. Another hydrogel similar to chitosan is a polysaccharide originated from natural chitin polymerization and has the antibacterial activity [86]. The bacterial adhesion and subsequent biofilm formation can be prevented by using chitosan alone. Several temperature-responsive structures of hydrogels (PLLA-PEG-PLLA, PDLA-CPC-PDLA, and PDLA-PEG-PDLA) were reported [87]. These hydrogels were performed to inhibit the growth of $S$. aureus and E. coli.

Titanium implants with different antibiotics (like gentamicin)-doped hydrogels coating significantly prevented the occurrence of infection. However, the methods of antibiotics hydrogel coating need to be optimized to reach suitable drug releasing profiles and optimal coating matrix degradation rate. Controlled delivery system loaded with drug on the titanium implants showed the double ability of antibacterial and osteogenesis forming by biodegradable sol-gel and polymers coating $[88,89]$. The controlled releasing technology of nanostructured sol-gel provided a continuous and effective local delivery system for orthopedic instruments to prevent and cure IRIs [90].

\section{Silver/silver ions coatings}

Most of the metal ions coating is in the form of ionic or nanoparticles instead of bulk material [91]. Silver ion is bioactive by wrecking the cell membrane permeability and cellular metabolism [91, 92]. The sulfhydryl groups of metabolic enzymes and bacterial DNA are disrupted by $\mathrm{Ag}$ to the destruction of bacterial membranes, so the bacterial key metabolism and replication are inactivated [92]. Implants coated with silver can prevent bacteria adhesion and subsequent colonization (like $S$. aureus and S. epidermidis) in vitro $[93,94]$. Titanium dioxide itself has been performed to be a kind of anti-infective biomaterials or cooperated with other factors $[95,96]$. However, implant with low-dose silver coating $(<1 \mathrm{ppm})$ may be incapable of reducing the infection rates [97], while high-dose silver coating (>1.5 ppm) may induce cytotoxicity [98]. However, cytotoxicity sensitivity is different among different cells [99-101]. Therefore, for the simple silver coating, the concentration of silver had better range from $1.8 \%$ to $6.5 \mathrm{wt} \%$ for inhibiting bacteria proliferation without decreasing osteoblast activity $[99,102]$. No observable adverse effect level (NOAEL) of silver is up to $30 \mathrm{mg} / \mathrm{kg}$ [103]. The most serious adverse effect of silver is Argyria, which is not found at or below $1.7 \mathrm{~g}$ total silver in vivo. For a long time release, the minimum requirement for antibacterial effect was at the concentrations of at least $0.1 \mathrm{ppb}[104,105]$. Another study reported that an optimal silver density on the implant surface was $1 \times 10^{18}$ ions $/ \mathrm{cm}^{2}$, representing a balance 
between corrosion resistance and antibacterial effect [106]. Unlike $\mathrm{Ag}^{+}$which is diffused to the surrounding tissue, a new antibacterial HA film was developed by immobilization of Ag in HA film through inositol hexaphosphate chelation. This antibacterial HA film coating demonstrated excellent antibacterial activity both in vitro and in vivo [107]. Data generated from a $S$. aureus induced in vivo osteomyelitis model demonstrated that no bacteria infection was detectable up to 21 days after implantation of implants with antibacterial HA film coating [107]. Ag-coated fracture external fixation pins were examined in human studies; however, these studies fail to demonstrate any advantages in reduction of pin site infections when silver-coated pins were used [108].

In summary, most studies have concentrated on these three kinds of materials coating. Other coating materials, such as iodine ions $[109,110]$, titanium oxide photocatalysis, nitric oxide, and graphene coating [111], have provided new ideas and alternative approaches for the prevention of IRIs.

\section{Evidence of the anti-infective prophylactic therapy of coating}

\section{In vitro studies}

Many studies using antimicrobial coatings have achieved on IRIs prevention in vitro. The therapeutic effects of antibacterial coating materials on the prevention of biofilm are usually evaluated by the in vitro zone inhibition of bacterial growth, such as S.aureus or MRSA [69, 112], antibiotic release profiles and bioactivities [70, 113, 114], cytotoxicity [67] of osteoblast, or other cell lines from the liver and kidney [104]. A characteristic time- and dose-dependent sustained antibiotics release is critical for the biofilm formation inhibition. David et al. tested a variety of antibiotics releasing efficacy and showed that all antibiotics used alone or in combination showed an initial burst release peak with dose-dependent antimicrobial effects and have no negative effects on osteoblast [112]. Local antibacterial spectrum and releasing curve for the biomaterial were needed to be considered when coating with antibiotics. The synthesized HA nanocrystals displayed antimicrobial effect against the IRIs by damaging bacteria membrane [69]. HA nanoparticles dispersed in the chitosan matrix lowered the burst releasing peak of the small molecule drug because of HA physisorption, which promoted persistent release kinetics up to 3 weeks [70]. The calcium phosphate coating can reduce burst release, which provided long-term release kinetics throughout 4 weeks [113]. Another team coated vancomycin onto PLLA/ $\beta$-TCP composites to release antibiotics through dip coating. The PLLA $/ \beta-T C P$ coating was biocompatible on cell proliferation, adhesion, and mineralization [67]. While gentamicin-doped poly(D,L-lactic acid) (PDLLA) coatings had an initial burst release and around $60 \%$ of incorporated drug was released within $1 \mathrm{~min}$. Then, a subsequent slow and constant release of gentamycin was observed lasting 6 weeks from $40 \%$ down to $15 \%$ [114].

Implants with antibiotic-doped coating suffered from a problem that antibiotic therapeutic concentrations lasted for a limited period time. When the antibiotic was exhausted, the antibiotic concentration was down to the levels enabling bacteria to escape antibiotic and colonize the implants [115]. Alternative approaches have been developed to tethering antibiotics on the surface of metal implants through a bridge linker and forming an immobilized antibacterial coating. The immobilized antibacterial coating is expected to be functional throughout the whole life of implants. Various types of antibiotics and bacterial membrane destructing molecules are suitable candidates for the preparation of immobilized antibacterial coating [116]. Compared to antibiotics, antimicrobial peptide was highly specific and had minimal toxicity to cells without drug resistance [117]. However, antimicrobial peptides are preferred for the treatment of IRIs instead of prevention.

\section{In vivo studies}

For mouse and rat model, $10^{5}$ colony-forming unit (CFU) bacterial suspension is often injected into the tibia bone marrow and fixed with different material steel pins $[64,118-120]$ Rat tibia implantation with bacterial infection[121] can be initiated by inoculation of a bacterial suspension at the site of implantation [122] or the use of a pre-colonized implant1. Mixed-models, involving the use of both a pre-colonized implant and a bacterial suspension [123], were reported to reproduce the clinical use of an infected implant and contaminated washing solutions at surgery, respectively. One limitation of the mixed models was the difficulty in distinguishing the biofilm formed on the implant from that of the inoculated bacterial suspension. Previous studies showed that inoculation of between $10^{2}$ and $10^{6} \mathrm{CFU}$ of $\mathrm{S}$. aureus showed similar histological changes [124, 125]. Results from in vivo were similar to in vitro demonstrating that biofilm was found on the implant surface on day 1 and then robustly proliferate on day 3 , persisting until day 7 . Biofilm formation was steady at $40 \%$ covering on day 14 [35]. Layer-by-layer (LBL) coatings were designed using the electrostatic multilayer assembly to get a programmable release [49], which was able to allow release antibiotics contained in upper layers in early stage that prevented the formation of biofilm followed by sustained antibiotics release in lower layers above MIC for 3-4 weeks [118]. These kinds of coatings provide two kinds of releasing curve to overcome drug deficiency during slow releasing. Beside antibiotics coatings, lysostaphin has been coated on the titanium implants and tested in a mouse model. Bacterial 
growth was almost totally inhibited, and a successful osseous healing was observed with lysostaphin-coated implants [119]. As mentioned earlier, ionic silver was immobilized on implant with hexaphosphate chelation by low heat immersion process. In mouse osteomyelitis model, there was no detectable bacterial presence 3 weeks after inoculation with S. aureus without burst releasing [107]. Gentamicin coating on titanium implants with gentamicinsodiumdodecylsulfate (SDS) and tannic acid demonstrated a high preventive effect on IRIs, which showed successful rapid osseointegration [64]. The rapid osseointegration is necessary which meant repairing completed. Gentamicin palmitate coating also significantly reduced IRIs on the implants as well as systemic inflammation [120]. PLLA/ $\beta$-TCP-coated implants loading with vancomycin presented favorable controlling IRIs and advancing bone osseointegration for 6 week [68].

Rabbit osteomyelitis model has been widely used for the evaluation of the antibacterial effect. Before fixed with different material steel pins, $10^{6}-10^{8} \mathrm{CFU}$ bacterial suspension is injected into the tibia bone marrow [126-128]. Polymer-Lipid Encapsulation MatriX (PLEX)-doxycycline-coated implants successfully avoided the occurrence of IRIs, even when rabbits were inoculation with a doxy-resistance strain [126]. The chitosan-calcium sulfate coating was reported to improve the therapeutic and preventive outcome of IRIs by prolonging the period of high releasing concentrations of antibiotic [127]. $\mathrm{Ti}_{6} \mathrm{Al}_{4} \mathrm{~V}$ pin coated vancomycin-chitosan/HA [74] and phosphatidylcholine [128] reached the similar results for the prophylaxis and therapy of IRIs. Local antibiotics release system can be easily used in surgery for IRIs by inhibiting biofilm biofilms formation on the implant surface [74, 128]. The abovementioned coating strategies are based on the traditional user-friendly technology and have some limitations in the release curve. While LBL formation by the deposition of hydrolytically poly (b-amino ester), poly (acrylic acid), and gentamicin were constructed without pre-modification. Interestingly, a burst-release peak of drug was over several days and followed by stable continuous zero-order release for weeks by hydrolytic erosion [63].

There are relatively few studies reported in using large size (dogs, miniature pigs, goat) animal models. Tran et al. created a titanium oxide combined with siloxane polymer coating doped with silver on intramedullary nails by metalorganic methods and tested in a goat osteomyelitis model with fracture. The tibia shaft fractures were created followed by the injection of $2 \times 10^{4} \mathrm{CFU}$ bacterial suspension in the osteotomy site. Then, a silver coated intramedullary nail was inserted for fixation. 5 weeks after fixation, the cured goat can walk by all four limbs without infection compared to the unwilling walking control, which suggested that the coated intramedullary implant as local antimicrobial releasing system for IRIs was feasible and effective [102]. In this research, the injection of bacterial suspension is low. Salgado CJ et al. established a model of tibial osteomyelitis by the injection of $4 \times 10^{9} \mathrm{CFU}$ bacterial suspension into osteotomy site [129]. However, there is lack of evidence to make sure the concentration of bacterial suspension for large size animal models.

\section{Clinical studies}

Until now, large randomized and multicenter clinical studies using antibacterial coating for the prevention of IRI were hard to be executed, because of the diversity of anti-infective coatings and the specificity of the manufacturing processes. Expert Tibia Nail (ETN) PROtect ${ }^{\mathrm{mm}}$ coated with a biodegradable gentamicin-laden polymer was used for IRIs. When it was used for the prophylaxis of osteomyelitis, no deep infections were observed after the placement of the gentamicin-coated nail and no side effects were reported that were linked to the implant coating $[65,130]$. Conway et al. used antibiotic cementcoated (ACC) rods for the control of IRIs by providing both the mechanical stability and local delivery of antibiotics. In this research, $60 \%$ of the patients were cured after the first procedure using ACC for infected arthrodesis and infected non-union and gets better functional rehabilitation. At last follow-up, 5 patients need amputation, illustrating a limb salvage rate of 105/110 (95\%) [131]. In the operating room Thonse et al. has used interlocking intramedullary nails coated with antibiotic cements before implantation. They found that the infection was well controlled in $95 \%(19 / 20)$ of treated patients, while the rest 1 patient had a union with infection and underwent an amputation unfortunately [132]. In a prospective, non-randomized case series, Fuchs et al. investigated the outcomes of 21 patients underwent surgical treatment with the gentamicin-loaded coating of an implant (UTN PROtect), and no implant-related infections occurred [133]. A 17-year-old man with grade IIIc tibial fractures was also treated by UTN-PROtect and has been successfully limb salvaged instead of prolonged external fixation or amputation which were the standard treatment [66]. Silver coated on the implant surface (Mutars ${ }^{\circ}$ tumor endoprosthesis (Implantcast, Buxtehude, Germany)) reduced the infection rate from 17.6 to $5.9 \%$ in patients with bone sarcoma [134]. Knee arthrodesis nail based on Mutars technology was successful in eradicating infection [135]. A case control study was conducted to examine the effect of silver-coated coatings, which showed the post-operative infection rate was $11.8 \%$ compared with $22.4 \%$ for the control group [136]. However, a report showed that local argyria occurred by Mutars ${ }^{\circ}$ tumor endoprosthesis though the length of the implant did not influence the development of local argyria [137]. Implants coated with iodine can be effective for preventing and 
treating IRIs. Two case series indicated that the rate of preventing or treating IRIs was over $95 \%$ with cytotoxicity and adverse effects $[109,110]$. A summary of above mentioned clinical studies was listed in Table 1 . The evidence of the research was weak because of the number and design of cases although kinds of coatings showed excellent effective for preventing and treating IRIs.

\section{Conclusion}

Prevention is better and more important than treatment for IRIs. The characteristics of time- and dose-dependence of biofilm formation require a more constant and sustained antibiotics release from implant coatings. Surface coating as one of implant surface fabrication approaches has been extensively investigated for the purpose of preventing and treating IRIs by either local antibiotics eluting or forming an antibacterial surface to resist the biofilm formation. A desired antibacterial implant coating is expected to enhance the adhesion and growth of host cells, while inhibiting bacterial adhesion and biofilm formation, so that host cells can be the winner in the "race to surface." The formation of biofilm and antibiotic resistance are time- and dosedependent, so that the antibacterial effect of coating should be sustained and constant at effective concentration at least for 4 weeks with a short-term releasing peak at 4-7 days. According to the characteristic of biofilms, layer by layer coating was more appropriate than monolayer coating for IRIs prevention.

S. aureus is one of the leading pathogens involved in IRIs [138]. As shown in Tande et al.'s [139] study that summarized the microbiological results of 2400 patients with IRIs, around $60 \%$ of IRIs was caused by $S$. aureus. Patients with $S$. aureus IRIs frequently have multiple medical comorbidities [140], such as diabetes (30 to 40\%) [141] and rheumatoid arthritis (10 to 20\%) [142]. Gentamicin and vancomycin are commonly used antibiotics for local drug eluting. For many years, antibiotic (gentamicin and vancomycin)-impregnated PMMA bone cement has been widely used to prevent IRIs [47]. Though PMMA cement is mechanically strong, the therapeutic efficacy of this treatment was questioned in recent studies. Major problems with antibiotic-loaded cements are their burst release and limited release of embedded antibiotics because of the diffusion through surface roughness, superficial pores, and surface erosion $[46,59]$. It is estimated that over $90 \%$ of loaded antibiotics are retained within the PMMA cement [58]. Regarding the IRIs prevention, the polymers hydrogel coating significantly extended the antibiotics release. The hydrogels release the drug steadily through the crosslinking structure [78-81]. Drug release is closely related to gel degradation through chemical bonds or ionic bonds [82-85]. The silver or silver ion coating seems to be the best way of prevention because of its broad antibacterial spectrum, a stable time- and dose-releasing effect, stable structure. But it has certain side effects on the human body, even if it is partially sustained releasing.

There are great opportunities and challenges to construct an ideal local drug delivery system. It is necessary to further establish a polymer system that has appropriate mechanical

Table 1 Published clinical data of different coatings

\begin{tabular}{|c|c|c|c|c|}
\hline Authors & Implant & Coating technology & Study type & $\begin{array}{l}\text { Evidence } \\
\text { level }\end{array}$ \\
\hline Moghaddam et al. [65] & Tibia nail (ETN PROtect ${ }^{\mathrm{TM}}$ ) & Gentamicin PLLA with "dip coating process" & Case series & IV \\
\hline Metsemakers et al. [130] & Tibia nail (ETN PROtect ${ }^{\mathrm{TM}}$ ) & Gentamicin PLLA with "dip coating process" & Case series & IV \\
\hline Conway et al. [131] & $\begin{array}{l}\text { Rods (antibiotic cement- } \\
\text { coated) }\end{array}$ & $\begin{array}{l}\text { Tobramycin and vancomycin cement (Biomet Cobalt) } \\
\text { with metal molds or silicone tubing }\end{array}$ & Case series & IV \\
\hline Thonse et al. [132] & $\begin{array}{l}\text { Interlocking intramedullary } \\
\text { (antibiotic cement-coated) }\end{array}$ & $\begin{array}{l}\text { Antibiotic powder Interlocking intramedullary wrap-ped } \\
\text { by cement (Zimmer, Warsaw, Indiana) with metal molds }\end{array}$ & Case series & IV \\
\hline Fuchs et al. [133] & Tibia nail (UTN PROtect) & Gentamicin PLLA with dip coating process & Case series & IV \\
\hline Raschke et al. [66] & Tibia nail (UTN PROtect) & Gentamicin PLLA with "dip coating process" & Case report & IV \\
\hline Hardes et al. [134] & Endoprosthesis (Mutars) & Silver with galvanic deposition & $\begin{array}{l}\text { Case control } \\
\text { study }\end{array}$ & III \\
\hline Wilding et al. [135] & Knee arthrodesis nail (Mutars) & Silver with galvanic deposition & Case series & IV \\
\hline Wafa et al. [136] & $\begin{array}{l}\text { Silver-enhanced custom-made } \\
\text { endoprostheses }\end{array}$ & Silver with anodisation of the titanium alloy & $\begin{array}{l}\text { Case control } \\
\text { study }\end{array}$ & III \\
\hline Glehr et al. [137] & Endoprosthesis (Mutars) & Silver with galvanic deposition & Case series & IV \\
\hline Shirai et al. [109] & $\begin{array}{l}\text { Kyocera Limb Salvage System } \\
\text { KOBELCO K-MAX }\end{array}$ & Povidone-iodine electrolyte-based process & Case series & IV \\
\hline Tsuchiya et al. [110] & $\begin{array}{l}\text { Spinal instrumentation, plates, } \\
\text { external fixator pins, prostheses, } \\
\text { nails, cannulated screw }\end{array}$ & Povidone-iodine electrolyte-based process & Case series & IV \\
\hline
\end{tabular}


strength, matrix formation, desired drug-releasing profiles, and is biodegradable in clinical application. Through data generated from many in vivo and in vitro studies were promising, there was lack of clinical trials for further validation. Therefore, future research should be concentrated on the clinical evaluation of polymer systems such as their clinical efficiency and analysis of post-operative surface of coatings. As for functional groups, drugs and agents can be improved in embedding method to achieve an ideal releasing curve, active ingredient, and conventional drug in new use or effective factors loaded.

In short, for modified implants, translational medicine is important. Whether the antibacterial polymer coatings are effective for prevention of IRIs or not needs clinical validation.

\section{Abbreviations \\ ACC: Antibiotic cement-coated; AFM: Atomic force microscopy; BCP: Bi- phasic calcium phosphates; CFU: Colony-forming units; CPC: Calcium phosphate cements; CWA: Cell wall-anchored; EPS: Extracellular polymeric substances; ETN: Expert Tibia Nail; FDA: American Food and Drug Administration; HA: Hydroxyapatite; IRIs: Implant related infections; LBL: Layer-by-layer; MBC: Minimal bactericidal concentration; MIC: Minimal inhibitory concentrations; MRSA: Methicillin resistant Staphylococcus aureus; NOAEL: No observable adverse effect level; PAA: Poly (acrylic acid); PDLLA: Poly(D,L-lactic acid); PEG: Polyethylene glycol; PEO: Polyethylene oxide; PIA: Polysaccharide intercellular adhesin; PLEX: Polymer-Lipid Encapsulation MatriX; PLLA: Poly(lactic acid); PMMA: Polymethylmethacrylate; PSMs: Phenol-soluble modulins; PVA: Poly (vinyl alcohol); RGD: Arginine- glycine-aspartic acid; SDS: Sodiumdodecylsulfate; SEM: Scanning electron microscope; $\beta$-TCP: Beta-tricalciumphosphate}

\section{Acknowledgements}

We would like to express our sincere thanks to Prof. Changqing Zhang and Shanghai Jiao Tong University Affiliated Sixth People's Hospital who have lent us hands in the course of writing this paper. And thanks for the comments on the amendment of the grammar and the supplement of the content from Prof. Weiping Ren (Department of Biomedical Engineering, Wayne State University College of Engineering, Detroit, MI).

\section{Funding}

This project was supported by National Natural Science Foundation of China (81572155).

\section{Authors' contributions}

$\mathrm{CP}$ and ZZ contributed equally to this work and should be considered as equal first coauthors. CP and ZZ conceived, drafted, and finalized the paper. $\mathrm{ZZ}$ and $\mathrm{XY}$ contributed to writing and finalizing the manuscript. All authors read and approved the final manuscript.

\section{Ethics approval and consent to participate}

Not applicable

\section{Consent for publication \\ Not applicable}

\section{Competing interests}

The authors declare that they have no competing interests.

\section{Publisher's Note}

Springer Nature remains neutral with regard to jurisdictional claims in published maps and institutional affiliations.
Received: 27 October 2017 Accepted: 22 August 2018

Published online: 03 September 2018

\section{References}

1. Mangram AJ, Horan TC, Pearson ML, Silver LC, Janvis WR. Guideline for prevention of surgical site infection, 1999. Hospital infection control practices advisory committee. Infect Control Hosp Epidemiol. 1999;20(4):250-78. quiz 79-80

2. Richards JE, Kauffmann RM, Obremskey WT, May AK. Stress-induced hyperglycemia as a risk factor for surgical-site infection in nondiabetic orthopedic trauma patients admitted to the intensive care unit. J Orthop Trauma. 2013:27(1):16-21.

3. Cook GE, Markel DC, Ren W, et al. Infection in orthopaedics. J Orthop Trauma. 2015;29(Suppl 12):S19-23.

4. Edmiston CE, Spencer M, Lewis BD, et al. Reducing the risk of surgical site infections: did we really think SCIP was going to lead us to the promised land? Surg Infect. 2011;12(3):169-77.

5. Cataldo MA, Petrosillo N, Cipriani M, Cauda R, Tacconelli E. Prosthetic joint infection: recent developments in diagnosis and management. J Inf Secur. 2010;61(6):443-8.

6. Williams DL, Haymond BS, Beck JP, et al. In vivo efficacy of a silicone-cationic steroid antimicrobial coating to prevent implant-related infection. Biomaterials. 2012 Nov:33(33):8641-56.

7. Yilmaz C, Colak M, Yilmaz BC, et al. Bacteriophage therapy in implant-related infections: an experimental study. J Bone Joint Surg Am. 2013:95(2):117-25.

8. Drago L, De Vecchi E. Microbiological diagnosis of implant-related infections: scientific evidence and cost/benefit analysis of routine antibiofilm processing. Adv Exp Med Biol. 2017;971:51-67.

9. Lovati AB, Bottagisio M, de Vecchi E, Gallazzi E, Drago L. Animal models of implant-related low-grade infections. A twenty-year review. Adv Exp Med Biol. 2017:971:29-50.

10. Romanò CL, Scarponi S, Gallazzi E, et al. Antibacterial coating of implants in orthopaedics and trauma: a classification proposal in an evolving panorama. J Orthop Surg Res. 2015;10:157.

11. Esteban J, Molina-Manso D, Spiliopoulou I, et al. Biofilm development by clinical isolates of Staphylococcus spp. from retrieved orthopedic prostheses. Acta Orthop. 2010;81(6):674-9.

12. Flemming HC, Wingender J. The biofilm matrix. Nat Rev Microbiol. 2010;8(9): $623-33$.

13. Drews J. Drug discovery: a historical perspective. Science. 2000;287(5460): 1960-4.

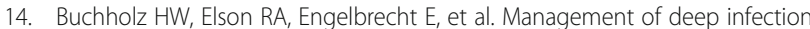
of total hip replacement. J Bone Joint Surg Br. 1981;63-B(3):342-53.

15. Simchi A, Tamjid E, Pishbin F, Boccaccini AR. Recent progress in inorganic and composite coatings with bactericidal capability for orthopaedic applications. Nanomedicine. 2011;7(1):22-39.

16. Vert M, Doi Y, Hellwich KH, et al. Terminology for biorelated polymers and applications (IUPAC Recommendations 2012). Pure Appl Chem. 2014;63(11-12): $377-410$.

17. Zhou $\mathrm{K}, \mathrm{Yu} \mathrm{H}, \mathrm{Li}$ J, et al. No difference in implant survivorship and clinical outcomes between full-cementless and full-cemented fixation in primary total knee arthroplasty: a systematic review and meta-analysis. Int J Surg. 2018;53:312-9

18. Qin S, Xu K, Nie B, Ji F, Zhang H. Approaches based on passive and active antibacterial coating on titanium to achieve antibacterial activity. J Biomed Mater Res A. 2018; https://doi.org/10.1002/jbm.a.36413.

19. Gkana EN, Doulgeraki Al, Chorianopoulos NG, Nychas GE. Anti-adhesion and anti-biofilm potential of organosilane nanoparticles against foodborne pathogens. Front Microbiol. 2017;11(8):1295.

20. Merghni A, Bekir K, Kadmi Y, et al. Adhesiveness of opportunistic Staphylococcus aureus to materials used in dental office: in vitro study. Microb Pathog. 2017;103: 129-34.

21. Berlanga M, Guerrero R. Living together in biofilms: the microbial cell factory and its biotechnological implications. Microb Cell Factories. 2016; 15(1):165.

22. Wassmann $T$, Kreis $S$, Behr M, Buergers $R$. The influence of surface texture and wettability on initial bacterial adhesion on titanium and zirconium oxide dental implants. Int J Implant Dent. 2017:3(1):32.

23. Liu P, Zhao Y, Yuan Z, et al. Construction of Zn-incorporated multilayer films to promote osteoblasts growth and reduce bacterial adhesion. Mater Sci Eng C Mater Biol Appl. 2017;75:998-1005. 
24. Lorenzetti M, Dogša I, Stošicki T, et al. The influence of surface modification on bacterial adhesion to titanium-based substrates. ACS Appl Mater Interfaces. 2015;7(3):1644-51.

25. Poon CY, Bhushan B. Comparison of surface roughness measurements by stylus profiler, AFM and non-contact profiler. Wear. 1995;190:76-88.

26. Mabboux F, Ponsonnet L, Morrier JJ, Jaffrezic N, Barsotti O. Surface free energy and bacterial retention to saliva-coated dental implant materials _ an in vitro study. Colloids Surf B Biointerfaces. 2004;25:199-205.

27. Weerkamp AH, van der Mei HC, Busscher HJ. The surface free energy of oral streptococci after being coated with saliva and its relation to adhesion in the mouth. J Dent Res. 1985;64:1204-10.

28. Verran J, Taylor RL, Lees GC. Bacterial adhesion to inert thermoplastic surfaces. J Mater Sci Mater Med. 1996:7:597.

29. Atefyekta S, Ercan B, Karlsson J, et al. Antimicrobial performance of mesoporous titania thin films: role of pore size, hydrophobicity, and antibiotic release. Int J Nanomedicine. 2016;11:977-90.

30. Grivet M, Morrier JJ, Benay G, Barsotti O. Effect of hydrophobicity on in vitro streptococcal adhesion to dental alloys. J Mater Sci Mater Med. 2000;11: 637-42.

31. Alam F, Balani K. Adhesion force of staphylococcus aureus on various biomaterial surfaces. J Mech Behav Biomed Mater. 2017:65:872-80.

32. Harris LG, Meredith DO, Eschbach L, Richards RG. Staphylococcus aureus adhesion to standard micro-rough and electropolished implant materials. J Mater Sci Mater Med. 2007;18(6):1151-6.

33. Albrektsson T, Wennerberg A. Oral implant surfaces: part 1-review focusing on topographic and chemical properties of different surfaces and in vivo responses to them. Int J Prosthodont. 2004;17:536-43.

34. Daddi Oubekka S, Briandet R, Fontaine-Aupart MP, Steenkeste K. Correlative time-resolved fluorescence microscopy to assess antibiotic diffusionreaction in biofilms. Antimicrob Agents Chemother. 2012;56(6):3349-58.

35. Nishitani K, Sutipornpalangkul W, de Mesy Bentley KL, et al. Quantifying the natural history of biofilm formation in vivo during the establishment of chronic implant-associated Staphylococcus aureus osteomyelitis in mice to identify critical pathogen and host factors. J Orthop Res. 2015;33(9):1311-9.

36. Brown MR, Allison DG, Gilbert P. Resistance of bacterial biofilms to antibiotics: a growth-rate related effect? J Antimicrob Chemother. 1988; 22(6):777-80.

37. Foster TJ, Geoghegan JA, Ganesh VK, Höök M. Adhesion, invasion and evasion: the many functions of the surface proteins of Staphylococcus aureus. Nat Rev Microbiol. 2014;12(1):49-62.

38. Moormeier DE, Bayles KW. Staphylococcus aureus biofilm: a complex developmental organism. Mol Microbiol. 2017;104(3):365-76.

39. Heilmann C, Schweitzer O, Gerke C, et al. Molecular basis of intercellular adhesion in the biofilm-forming Staphylococcus epidermidis. Mol Microbiol. 1996;20(5):1083-91.

40. Arciola CR, Campoccia D, Ravaioli S, Montanaro L. Polysaccharide intercellular adhesin in biofilm: structural and regulatory aspects. Front Cell Infect Microbiol. 2015;5:7

41. Le KY, Dastgheyb S, Ho TV, Otto M. Molecular determinants of staphylococcal biofilm dispersal and structuring. Front Cell Infect Microbiol. 2014;4:167.

42. Clarissa P, Waters EM, Rudkin JK, Schaeffer CR, Lohan AJ, Tong P, Loftus BJ, Pier GB, Fey PD, Massey RC. Methicillin resistance alters the biofilm phenotype and attenuates virulence inStaphylococcus aureus deviceassociated infections. PLoS Pathog. 2012:8(4):e1002626.

43. Sánchez MC, Llama-Palacios A, Fernández E, et al. An in vitro biofilm model associated to dental implants: structural and quantitative analysis of in vitro biofilm formation on different dental implant surfaces. Dent Mater. 2014; 30(10):1161-71.

44. Roehling S, Astasov-Frauenhoffer M, Hauser-Gerspach I, et al. In vitro biofilm formation on titanium and zirconia implant surfaces. J Periodontol. 2017; 88(3):298-307.

45. Jiranek WA, Hanssen AD, Greenwald AS. Antibiotic-loaded bone cement for infection prophylaxis in total joint replacement. J Bone Joint Surg Am. 2006; 88(11):2487-500.

46. Wu T, Zhang $Q$, Ren $W$, et al. Controlled release of gentamicin from gelatin/ genipin reinforced beta-tricalcium phosphate scaffold for the treatment of osteomyelitis. J Mater Chem B. 2013;1(26):3304-13.

47. Walenkamp GH, Kleijn LL, de Leeuw M. Osteomyelitis treated with gentamicin-PMMA beads: 100 patients followed for 1-12 years. Acta Orthop Scand. 1998;69(5):518-22
48. Wei Q, Haag R. Universal polymer coatings and their representative biomedical applications. Mater Horiz. 2015:2(6):567-77.

49. Wei Q, Becherer T, Angioletti-Uberti S, et al. Protein interactions with polymer coatings and biomaterials. Angew Chem Int Ed Engl. 2014;53(31): 8004-31.

50. Boles BR, Thoendel M, Singh PK. Self-generated diversity produces "insurance effects" in biofilm communities. Proc Natl Acad Sci U S A. 2004; 101(47):16630-5.

51. Sanchez-Gomez S, Ferrer-Espada R, Stewart PS, et al. Antimicrobial activity of synthetic cationic peptides and lipopeptides derived from human lactoferricin against Pseudomonas aeruginosa planktonic cultures and biofilms. BMC Microbiol. 2015;15:137.

52. Davies JA, Harrison JJ, Marques LL, et al. The GacS sensor kinase controls phenotypic reversion of small colony variants isolated from biofilms of Pseudomonas aeruginosa PA14. FEMS Microbiol Ecol. 2007:59(1):32-46.

53. Harrison JJ, Ceri H, Turner RJ. Multimetal resistance and tolerance in microbial biofilms. Nat Rev Microbiol. 2007:5(12):928-38.

54. Maisonneuve E, Gerdes K. Molecular mechanisms underlying bacterial persisters. Cell. 2014;157(3):539-48.

55. Benoit MA, Mousset B, Delloye C, Bouillet R, Gillard J. Antibiotic-loaded plaster of Paris implants coated with poly lactide-co-glycolide as a controlled release delivery system for the treatment of bone infections. Int Orthop. 1997;21(6): 403-8.

56. Webb JC, Spencer RF. The role of polymethylmethacrylate bone cement in modern orthopaedic surgery. J Bone Joint Surg Br. 2007;89(7):851.

57. Zilberman M, Elsner JJ. Antibiotic-eluting medical devices for various applications. J Control Release. 2008;130(3):202-15.

58. Zhou Z, Seta J, Markel DC, et al. Release of vancomycin and tobramycin from polymethylmethacrylate cements impregnated with calcium polyphosphate hydrogel. J Biomed Mater Res B Appl Biomater. 2017; https://doi.org/10.1002/jbm.b.34063

59. Wu TY, Zhou ZB, He ZW, et al. Reinforcement of a new calcium phosphate cement with RGD-chitosan-fiber. J Biomed Mater Res A. 2014;102(1):68-75.

60. Bohner M, Gbureck U, Barralet JE. Technological issues for the development of more efficient calcium phosphate bone cements: a critical assessment. Biomaterials. 2005:26(33):6423-9.

61. Wu T, Hua X, He Z, et al. The bactericidal and biocompatible characteristics of reinforced calcium phosphate cements. Biomed Mater. 2012;7(4):045003.

62. Chen WC, Lin JH, Ju CP. Transmission electron microscopic study on setting mechanism of tetracalcium phosphate/dicalcium phosphate anhydrousbased calcium phosphate cement. J Biomed Mater Res A. 2003;64(4):664-71.

63. Moskowitz JS, Blaisse MR, Samuel RE, et al. The effectiveness of the controlled release of gentamicin from polyelectrolyte multilayers in the treatment of Staphylococcus aureus infection in a rabbit bone model. Biomaterials. 2010:31(23):6019-30.

64. Diefenbeck M, Schrader C, Gras F, et al. Gentamicin coating of plasma chemical oxidized titanium alloy prevents implant-related osteomyelitis in rats. Biomaterials. 2016;101:156-64.

65. Moghaddam A, Graeser $V$, Westhauser F, et al. Patients' safety: is there a systemic release of gentamicin by gentamicin-coated tibia nails in clinical use? Ther Clin Risk Manag. 2016;12:1387-93.

66. Raschke M, Vordemvenne T, Fuchs T. Limb salvage or amputation? The use of a gentamicin coated nail in a severe, grade Illc tibia fracture. Eur J Trauma Emerg Surg. 2010;36(6):605-8.

67. Kankilic B, Bayramli E, Kilic E, Dağdeviren S, Korkusuz F. Vancomycin containing PLLA/B-TCP controls MRSA in vitro. Clin Orthop Relat R. 2011;469(11):3222-8.

68. Kankilic B, Bilgic E, Korkusuz P, Korkusuz F. Vancomycin containing PLLA/ beta-TCP controls experimental osteomyelitis in vivo. J Orthop Surg Res. 2014;9:114.

69. Baskar K, Anusuya T, Devanand Venkatasubbu G. Mechanistic investigation on microbial toxicity of nano hydroxyapatite on implant associated pathogens. Mater Sci Eng C Mater Biol Appl. 2017;73:8-14.

70. Uskokovic V, Desai TA. In vitro analysis of nanoparticulate hydroxyapatite/chitosan composites as potential drug delivery platforms for the sustained release of antibiotics in the treatment of osteomyelitis. J Pharm Sci. 2014;103(2):567-79.

71. Xie XH, Yu XW, Zeng SX, et al. Enhanced osteointegration of orthopaedic implant gradient coating composed of bioactive glass and nanohydroxyapatite. J Mater Sci Mater Med. 2010:21(7):2165-73.

72. Xiu P, Jia Z, Lv J, et al. Hierarchical micropore/nanorod apatite hybrids insitu grown from 3-D printed macroporous Ti6Al4V implants with improved bioactivity and osseointegration. J Mater Sci Technol. 2017;2:179-86. 
73. Shah FA, Trobos M, Thomsen P, Palmquist A. Commercially pure titanium (cp-Ti) versus titanium alloy $\left(\mathrm{Ti}_{6} \mathrm{Al}_{4} \mathrm{~V}\right)$ materials as bone anchored implants - is one truly better than the other? Mater Sci Eng C Mater Biol Appl. 2016;62:960-6.

74. Yang CC, Lin CC, Liao JW, Yen SK. Vancomycin-chitosan composite deposited on post porous hydroxyapatite coated Ti6Al4V implant for drug controlled release. Mater Sci Eng C Mater Biol Appl. 2013;33(4):2203-12.

75. Dorozhkin SV. Biphasic, triphasic and multiphasic calcium orthophosphates. Acta Biomater. 2012;8(3):963-77.

76. Polak SJ, Levengood SK, Wheeler MB, et al. Analysis of the roles of microporosity and BMP-2 on multiple measures of bone regeneration and healing in calcium phosphate scaffolds. Acta Biomater. 2011;7(4): 1760-71.

77. Li X, Wei J, Aifantis KE, et al. Current investigations into magnetic nanoparticles for biomedical applications. J Biomed Mater Res A. 2016; 104(5):1285-96.

78. Razavi M, Fathi M, Savabi O, Vashaee D, Tayebi L. In vivo study of nanostructured akermanite/PEO coating on biodegradable magnesium alloy for biomedical applications. J Biomed Mater Res A. 2015;103(5):1798-808.

79. Oh S, Moon KS, Lee SH. Effect of RGD peptide-coated TiO2 nanotubes on the attachment, proliferation, and functionality of bone-related cells. J Nanomater. 2013;2013(13):125-8.

80. Marchesan S, Qu Y, Waddington $\sqcup$, et al. Self-assembly of ciprofloxacin and a tripeptide into an antimicrobial nanostructured hydrogel. Biomaterials. 2013;34(14):3678-87.

81. Chang $\mathrm{CH}$, Lin $\mathrm{YH}$, Yeh $\mathrm{CL}$, et al. Nanoparticles incorporated in $\mathrm{pH}$-sensitive hydrogels as amoxicillin delivery for eradication of helicobacter pylori. Biomacromolecules. 2010;11(1):133.

82. Li H, Yang J, Hu X, et al. Superabsorbent polysaccharide hydrogels based on pullulan derivate as antibacterial release wound dressing. J Biomed Mater Res A. 2011;98(1):31.

83. Rabea El, Badawy ET, Stevens CV, Smagghe G, Steurbaut W. Chitosan as antimicrobial agent: applications and mode of action. Biomacromolecules. 2015;4(6):1457

84. Xiao B, Wan Y, Zhao M, Liu Y, Zhang S. Preparation and characterization of antimicrobial chitosan- $\mathrm{N}$-arginine with different degrees of substitution. Carbohydr Polym. 2011;83(1):144-50.

85. Hashemi DA, Mirzadeh H, Imani M, Samadi N. Chitosan/polyethylene glycol fumarate blend film: physical and antibacterial properties. Carbohydr Polym. 2013;92(1):48-56.

86. Dai T, Tanaka M, Huang YY, Hamblin MR. Chitosan preparations for wounds and burns: antimicrobial and wound-healing effects. Expert Rev Anti-Infe. 2011;9(7):857

87. Yan L, Kazuki F, Coady DJ, et al. Broad-spectrum antimicrobial and biofilmdisrupting hydrogels: stereocomplex-driven supramolecular assemblies. Angew Chem. 2013;52(2):674.

88. Guillaume O, Garric X, Lavigne JP, Van DBH, Coudane J. Multilayer, degradable coating as a carrier for the sustained release of antibiotics: preparation and antimicrobial efficacy in vitro. J Control Release. 2012;162(3):492-501.

89. Tang $Y$, Zhao $Y$, Wang $H$, et al. Layer-by-layer assembly of antibacterial coating on interbonded 3D fibrous scaffolds and its cytocompatibility assessment. J Biomed Mater Res A. 2012;100A(8):2071-8.

90. Qu H, Knabe $C$, Burke $M$, et al. Bactericidal micron-thin sol-gel films prevent pin tract and periprosthetic infection. Mil Med. 2014;179(8 Suppl):29-33.

91. Lemire JA, Harrison JJ, Turner RJ. Antimicrobial activity of metals: mechanisms, molecular targets and applications. Nat Rev Microbiol. 2013;11(6):371-84.

92. Feng QL, Wu J, Chen GQ, et al. A mechanistic study of the antibacterial effect of silver ions on Escherichia coli and Staphylococcus aureus. J Biomed Mater Res. 2015;52(4):662-8.

93. Chen W, Oh S, Ong AP, et al. Antibacterial and osteogenic properties of silver-containing hydroxyapatite coatings produced using a sol gel process. J Biomed Mater Res A. 2010;82A(4):899-906.

94. Zheng Z, Yin W, Zara JN, et al. The use of BMP-2 coupled - nanosilver-PLGA composite grafts to induce bone repair in grossly infected segmental defects. Biomaterials. 2010;31(35):9293-300.

95. Chernousova S, Epple M. Silver as antibacterial agent: ion, nanoparticle, and metal. Angew Chem Int Ed Engl. 2013;52(6):1636-53.

96. Mijnendonckx K, Leys N, Mahillon J, Silver S, Houdt RV. Antimicrobial silver: uses, toxicity and potential for resistance. Biometals. 2013;26(4): 609.
97. Harrasser N, Gorkotte J, Obermeier A, et al. A new model of implant-related osteomyelitis in the metaphysis of rat tibiae. BMC Musculoskel Dis. 2016; $17(1): 1-11$.

98. Agarwal A, Weis TL, Schurr MJ, et al. Surfaces modified with nanometerthick silver-impregnated polymeric films that kill bacteria but support growth of mammalian cells. Biomaterials. 2010;31(4):680-90.

99. Bai X, Sandukas S, Appleford M, Ong JL, Rabiei A. Antibacterial effect and cytotoxicity of Ag-doped functionally graded hydroxyapatite coatings. J Biomed Mater Res B Appl Biomater. 2012;100(2):553-61.

100. Singh A, Dar MY, Joshi B, et al. Phytofabrication of silver nanoparticles: novel drug to overcome hepatocellular ailments. Toxicol Rep. 2018;5:333-42.

101. Dakal TC, Kumar A, Majumdar RS, Yadav V. Mechanistic basis of antimicrobial actions of silver nanoparticles. Front Microbiol. 2016;7:1831.

102. Tran N, Tran PA, Jarrell JD, et al. In vivo caprine model for osteomyelitis and evaluation of biofilm-resistant intramedullary nails. Biomed Res Int. 2013; 2013:674378.

103. Kim YS, Song MY, Park JD. Subchronic oral toxicity of silver nanoparticles. Part Fibre Toxicol. 2010;7:20. https://doi.org/10.1186/1743-8977-7-20.

104. Nandi SK, Shivaram A, Bose S, Bandyopadhyay A. Silver nanoparticle deposited implants to treat osteomyelitis. J Biomed Mater Res B Appl Biomater. 2018;106(3):1073-83.

105. Kundu B, Nandi SK, Roy S, et al. Systematic approach to treat chronic osteomyelitis through ceftriaxone-sulbactam impregnated porous $\beta$-tri calcium phosphate localized delivery system. Ceram Int. 2012;38:1533-48.

106. Zhao J, Feng $\mathrm{HJ}$, Tang HQ, Zheng JH. Bactericidal and corrosive properties of silver implanted TiN thin films coated on AISI317 stainless steel. Surf Coat Tech. 2007;201(9):5676-9.

107. Funao $H$, Nagai S, Sasaki A, et al. A novel hydroxyapatite film coated with ionic silver via inositol hexaphosphate chelation prevents implantassociated infection. Sci Rep. 2016:6:23238.

108. Coester LM, Nepola JV, Allen J, Marsh JL. The effects of silver coated external fixation pins. lowa Orthop J. 2006:26:48-53.

109. Shirai T, Tsuchiya H, Nishida H, et al. Antimicrobial megaprostheses supported with iodine. J Biomater Appl. 2014;29(4):617-23.

110. Tsuchiya $H$, Shirai $T$, Nishida $H$, et al. Innovative antimicrobial coating of titanium implants with iodine. J Orthop Sci. 2012;17(5):595-604.

111. Zhou Z, Xu Z, Wang F, et al. New strategy to rescue the inhibition of osteogenesis of human bone marrow-derived mesenchymal stem cells under oxidative stress: combination of vitamin $C$ and graphene foams. Oncotarget. 2016:7(44):71998-2010.

112. Back DA, Bormann N, Calafi A, et al. Testing of antibiotic releasing implant coatings to fight bacteria in combat-associated osteomyelitis - an in-vitro study. Int Orthop. 2016;40(5):1039-47.

113. Bastari $\mathrm{K}$, Arshath $\mathrm{M}, \mathrm{Ng} \mathrm{ZH}$, et al. A controlled release of antibiotics from calcium phosphate-coated poly(lactic-co-glycolic acid) particles and their in vitro efficacy against Staphylococcus aureus biofilm. J Mater Sci Mater Med. 2014:25(3):747-57.

114. Vester H, Wildemann B, Schmidmaier G, Stockle U, Lucke M. Gentamycin delivered from a PDLLA coating of metallic implants: in vivo and in vitro characterisation for local prophylaxis of implant-related osteomyelitis. Injury. 2010;41(10):1053-9.

115. Hickok NJ, Shapiro IM. Immobilized antibiotics to prevent orthopaedic implant infections is. Adv Drug Deliv Rev. 2012;64(12):1165-76.

116. Jr VA, Adams CS, Parvizi J, et al. The inhibition of Staphylococcus epidermidis biofilm formation by vancomycin-modified titanium alloy and implications for the treatment of periprosthetic infection. Biomaterials. 2008;29(35):4684-90.

117. Héquet A, Humblot V, Berjeaud JM, Pradier CM. Optimized grafting of antimicrobial peptides on stainless steel surface and biofilm resistance tests. Colloid Surfaces B. 2011;84(2):301-9.

118. Min J, Choi KY, Dreaden EC, et al. Designer dual therapy nanolayered implant coatings eradicate biofilms and accelerate bone tissue repair. ACS Nano. 2016;10(4):4441-50.

119. Windolf CD, Logters T, Scholz M, Windolf J, Flohe S. Lysostaphin-coated titan-implants preventing localized osteitis by Staphylococcus aureus in a mouse model. PLoS One. 2014;9(12):e115940.

120. Folsch C, Federmann M, Kuehn KD, et al. Coating with a novel gentamicinpalmitate formulation prevents implant-associated osteomyelitis induced by methicillin-susceptible Staphylococcus aureus in a rat model. Int Orthop. 2015;39(5):981-8.

121. Monzón M, García-Alvarez F, Laclériga A, et al. A simple infection model using pre-colonized implants to reproduce rat chronic Staphylococcus 
aureus osteomyelitis and study antibiotic treatment. J Orthop Res. 2001; 19(5):820-6.

122. Power ME, Olson ME, Domingue PA, Costerton JW. A rat model of Staphylococcus aureus chronic osteomyelitis that provides a suitable system for studying the human infection. J Med Microbiol. 1990;33(3):189-98.

123. Gracia E, Laclériga A, Monzón M, et al. Application of a rat osteomyelitis model to compare in vivo and in vitro the antibiotic efficacy against bacteria with high capacity to form biofilms. J Surg Res. 1998;79(2):146-53

124. Lucke M, Schmidmaier G, Sadoni S, et al. A new model of implant-related osteomyelitis in rats. J Biomed Mater Res B Appl Biomater. 2003;67(1):593602.

125. Ren W, Muzik O, Jackson N, et al. Differentiation of septic and aseptic loosening by PET with both 11C-PK11195 and 18F-FDG in rat models. Nuc Med Commun. 2012;33(7):747-56.

126. Metsemakers WJ, Emanuel N, Cohen O, et al. A doxycycline-loaded polymer-lipid encapsulation matrix coating for the prevention of implantrelated osteomyelitis due to doxycycline-resistant methicillin-resistant Staphylococcus aureus. J Control Release. 2015;209:47-56.

127. Beenken KE, Smith JK, Skinner RA, et al. Chitosan coating to enhance the therapeutic efficacy of calcium sulfate-based antibiotic therapy in the treatment of chronic osteomyelitis. J Biomater Appl. 2014;29(4): 514-23.

128. Jennings JA, Beenken KE, Skinner RA, et al. Antibiotic-loaded phosphatidylcholine inhibits staphylococcal bone infection. World J Orthop. 2016;7(8):467-74

129. Salgado CJ, Jamali AA, Mardini S, Buchanan K, Veit B. A model for chronic osteomyelitis using Staphylococcus aureus in goats. Clin Orthop Relat Res. 2005;436:246-50.

130. Metsemakers WJ, Reul M, Nijs S. The use of gentamicin-coated nails in complex open tibia fracture and revision cases: a retrospective analysis of a single Centre case series and review of the literature. Injury. 2015;46(12): 2433-7.

131. Conway J, Mansour J, Kotze K, Specht S, Shabtai L. Antibiotic cement-coated rods: an effective treatment for infected long bones and prosthetic joint nonunions. Bone Joint J. 2014;96-b(10):1349-54.

132. Thonse R, Conway J. Antibiotic cement-coated interlocking nail for the treatment of infected nonunions and segmental bone defects. J Orthop Traum. 2007;21(4):258-68.

133. Fuchs T, Stange R, Schmidmaier G, Raschke MJ. The use of gentamicincoated nails in the tibia: preliminary results of a prospective study. Arch Orthop Trauma Surg. 2011;131(10):1419-25.

134. Hardes J, von Eiff C, Streitbuerger A, et al. Reduction of periprosthetic infection with silver-coated megaprostheses in patients with bone sarcoma. J Surg Oncol. 2010;101(5):389-95.

135. Wilding CP, Cooper GA, Freeman AK, Parry MC, Jeys L. Can a silver-coated arthrodesis implant provide a viable alternative to above knee amputation in the unsalvageable, infected total knee arthroplasty? J Arthroplast. 2016; 31(11):2542-7.

136. Wafa H, Grimer RJ, Reddy K, Jeys L, Abudu A, Carter SR, Tillman RM. Retrospective evaluation of the incidence of early periprosthetic infection with silver-treated endoprostheses in high-risk patients: case-control study. Bone Joint J. 2015;97-B(2):252-7.

137. Glehr M, Leithner A, Friesenbichler J, et al. Argyria following the use of silver-coated megaprostheses: no association between the development of local argyria and elevated silver levels. Bone Joint J. 2013;95-B(7): 988-92.

138. Pulido L, Ghanem E, Joshi A, Purtill JJ, Parvizi J, et al. Periprosthetic joint infection: the incidence, timing, and predisposing factors. Clin Orthop Relat Res. 2008:466(7):1710-5.

139. Tande AJ, Patel R. Prosthetic joint infection. Clin Microbiol Rev. 2014;27(2): 302-45.

140. Sendi P, Banderet F, Graber P, Zimmerli W. Clinical comparison between exogenous and haematogenous periprosthetic joint infections caused by Staphylococcus aureus. Clin Microbiol Infect. 2011;17(7):1098-100.

141. Senneville $E$, Joulie $D$, Legout $L$, et al. Outcome and predictors of treatment failure in total hip/knee prosthetic joint infections due to Staphylococcus aureus. Clin Infect Dis. 2011;53(4):334-40.

142. Lora-Tamayo J, Murillo O, Iribarren JA, et al. A large multicenter study of methicillin-susceptible and methicillin-resistant Staphylococcus aureus prosthetic joint infections managed with implant retention. Clin Infect Dis. 2013;56(2):182-94.

Ready to submit your research? Choose BMC and benefit from:

- fast, convenient online submission

- thorough peer review by experienced researchers in your field

- rapid publication on acceptance

- support for research data, including large and complex data types

- gold Open Access which fosters wider collaboration and increased citations

- maximum visibility for your research: over $100 \mathrm{M}$ website views per year

At $\mathrm{BMC}$, research is always in progress.

Learn more biomedcentral.com/submissions 